\title{
N1b Stage Finding
}

National Cancer Institute

\section{Source}

National Cancer Institute. N1b Stage Finding. NCI Thesaurus. Code C48708.

A general term that refers to a TNM finding of cancer metastases usually in a limited number of regional lymph nodes. The definition of N1b TNM finding depends on the specific type of cancer that it refers to; for example, for breast cancer it refers to metastases in internal mammary lymph nodes with micrometastases or macrometastases detected by sentinel lymph node biopsy but not clinically detected; for cutaneous melanoma it refers to macrometastasis in one regional lymph node; for colorectal cancer it refers to metastasis in 2-3 regional lymph nodes. 